\title{
PROPOSTAS HERMENÊUTICAS DE APLICAÇÃO DO DIREITO E MITIGAÇÃO DA DISCRICIONARIEDADE JUDICIAL
}

Túlio de Medeiros Jales ${ }^{406}$

Recebido em:14/02/2016

Aprovado em: 15/08/2016

\begin{abstract}
RESUMO
O trabalho apresenta as teorias hermenêuticas para interpretação e aplicação do direito como formulações que pretendem constranger a discricionariedade judicial a um nível que as teorias argumentativas não ousam chegar. A Tese da Resposta Adequada à Constituição oferecida pelo movimento Crítica Hermenêutica do Direito será o referencial hermenêutico que servirá de amostra para demonstrar que um constrangimento da tradição jurídica é sim capaz de operar restrições ao ato de aplicação do direito pelo intérprete.
\end{abstract}

Palavras-Chave: Hermenêutica Jurídica. Hermenêutica Filosófica. Crítica Hermenêutica do Direito. Teoria da Resposta Adequada à Constituição.

\section{INTRODUÇÃO}

As abordagens argumentativas sobre a decisão, alterando a conceituação de segurança jurídica, passam a não ver a carência de padrões decisórios como um problema em si, concedendo ao julgador uma margem de discricionariedade para escolher entre diversas soluções possíveis, avaliando e controlando esta escolha somente pela suficiência ou não de sua justificação. Assim, o enfoque prioritariamente hermenêutico entenderá a discricionariedade como um problema com contornos diferentes da forma como as teorias argumentativas o visualizam, envidando esforços para elaborar meios de controle da própria atribuição do sentido das normas.

Justamente por se propor a realizar um trabalho que as abordagens argumentativas entendem ser impossível de concretizar-se é que as teorias hermenêuticas serão analisadas na presente investigação. É dizer, o objetivo específico da pesquisa será por em análise a validade

\footnotetext{
${ }^{406}$ Mestrando em Direito Constitucional pela Universidade Federal do Rio Grande do Norte. Endereço eletrônico: tulio_jales@hotmail.com.
} 
das soluções que as abordagens hermenêuticas da decisão judicial oferecem aos juristas para pôr fim o problema da falta de padronização e harmonia entre as decisões judiciais.

Assume-se, todavia, que não existe apenas uma abordagem específica dentro deste epíteto genérico (não positivista de fundo hermenêutico), sendo necessário escolher uma corrente particular para tomar como amostra e avaliar a força da proposta hermenêutica.

A pesquisa opta, então, por estudar a fundo a formulação da intitulada Crítica Hermenêutica do Direito (CHD), movimento acadêmico capitaneado pelo Prof. Lênio Luiz Streck que, relacionando a hermenêutica filosófica com a teoria do direito, esforça-se em imprimir ao momento da decisão judicial os atributos da coerência e integridade.

Três fatores explicam sumária, mas suficientemente, a escolha pela pesquisa a partir do referencial do Professor Lênio Streck. O primeiro é o reconhecimento da força que a elaboração teórica de sua escola vem ganhando na academia nacional, sendo enxergada como uma das mais importantes críticas ao fenômeno da discricionariedade nas decisões judiciais; sendo um autor que tem o local de fala em nosso sistema jurídico, possibilita-se conectar mais facilmente um tema eminentemente teórico de hermenêutica jurídica com a realidade prática nacional; por fim, através da leitura da CHD possibilita-se de analisar as teses de autores internacionalmente debatidos como Ronald Dworkin e Hans-Georg Gadamer, pois são esses os dois principais jusfilósofos inspiradores da obra streckiana.

O trabalho, pois, decantará os argumentos do movimento teórico escolhido, bem como avaliará a intutulada "Teoria da Resposta Constitucionalmente Adequada" (TRCA) apresentada por Streck, como alternativa para que se mitigue o problema hermenêutico da decisão judicial. A relação que esta teoria esboça entre a moral comunitária e a função da jurisprudência como instância de essencial para a manutenção da coerência e da integridade do sistema receberá um cuidado especial da análise, haja em conta ser este o ponto de contato entre a teoria exposta e a análise da forma como o NCPC trata a decisão judicial na sua dimensão hermenêutica.

\section{A DISCRICICIONARIDADE JUDICIAL NO PÓS POSITIVISMO}

A zona de convergência a enlaçar as diferentes propostas não positivistas, ou pós positivista é a admissão da necessária relação conceitual entre o direito e a moral, pela qual critérios morais passariam a informar e restringir a margem de discricionariedade dos juízes. No espaço interpretativo onde antes não havia direito e aí se desenvolveria a discricionariedade agora passam a existir parâmetros de natureza cogente. A forma como tais padrões, agora de 
cariz normativo, seriam lidos e ou expressados para que possam ser avaliados pelo sistema será face de divergência entre as correntes não positivistas.

Em termos de argumentação, temos que a evolução das teorias argumentativas entre os séculos XX e XXI passou a encarar o problema da discricionariedade com outras lentes. Deixou-se de compreender que a existência de respostas diversas para um mesmo problema jurídico significasse uma quebra de segurança do sistema. Esta passaria a estar garantida com a adoção de critérios de correção argumentativa fornecidos pela tópica, pela retórica ou pela teoria da argumentação, que seriam capazes de imprimir um nível de racionalidade na interpretação e aplicação do direito sem pretender desembocar, no entanto, no desvelamento de uma resposta correta ou de uma resposta jurisdicional mais adequada (RODRIGUEZ, 2013, p. 161). O caro às teorias argumentativas é a maneira pela qual os Juízes apresentam sua decisão, cumprindo ou não percursos lógicos cristalizados em determinado modelo de justificação.

Navega-se, então, em meio a uma onda normativa (não mais analítica, no sentido da dualidade anteriormente proposta) da teoria do direito, detentora da pretensão de prescrever quais seriam as decisões corretas nos casos concretos (BUSTAMANTE, 2008, p. 360). Em tais assunções, à discricionariedade é reservado um espaço amplo, isto é, concede-se um espectro considerável ao momento de criação do Juiz, mas a este reconhecimento acopla-se um modelo de justificação racional da decisão. Em um modelo de justificação ideal deste gênero os requisitos de justificação obteriam sucesso não por chegarem a uma suposta verdade interpretativa escondida no ordenamento, mas por convencerem as partes e os cidadãos em geral de que a decisão alcançada é aceitável e inserida na moldura destinada ao processo criativo do Juiz (RODRIGUEZ, 2013, p.162).

Buscando uma conceituação ampla para amalgamar, a partir de suas características comuns, parte das importantes teorias da argumentação desenvolvidas ao longo do século XX, Bustamante (2008, p. 363) reúne as diferentes propostas como "teorias sobre o emprego de argumentos e o valor de cada um deles nos discursos de justificação de uma decisão jurídica, visando a um incremento de racionalidade na fundamentação e aplicação da prática do direito, na máxima medida possível”.

José Rodrigo Rodriguez (RODRIGUEZ et al, 2010, p. 86), buscando analisar em termos argumentativos as decisões tomadas pela jurisdição constitucional brasileira, concluiu-se que é impossível afirmar a preponderância de um determinado modelo de argumentação jurídica mobilizado pelos magistrados, percebendo-se a convivência conflituosa de diversos parâmetros de argumentação e de racionalidade. 
Tal conclusão não surpreende se percebemos que a forma de encarar a discricionariedade com as lentes da moderna argumentação jurídica não adota, majoritariamente um meta critério de validação das racionalidades jurídicas em disputa Isto é, compreendendo um discurso racional como aquele "em que os falantes levantam pretensões de validade e são capazes de defendê-la sem entrar em contradição, quando instados a fazê-lo" (RODRIGUEZ, 2013, p.173), não haverá uma instância final em que se definam como corretas ou não as pretensões de validade, mas sim instâncias que julguem as racionalidades como base em pretensões de validade já previamente assumidas.

Como se apercebe, a visão da discricionariedade pelo horizonte argumentativo não reclama um meta-critério argumentativo que indique qual teoria da argumentação melhor justifica uma decisão. A convivência de diversos parâmetros de racionalidade jurídica é vista por certos teóricos, inclusive, como algo positivo, pois "permite que o direito lide com sociedades plurais e altamente complexas" (RODRIGUEZ, 2013, p. 171), absorvendo e estabilizando em compromissos temporários os diversos discursos racionais dos diferentes atores sociais que disputam a interpretação.

O problema estaria, aí sim, quando inexistisse qualquer racionalidade na decisão tomada ou quando não se possa identificar um padrão de racionalidade determinado, passando a ser o exercício do decidir um ato arbitrário e sem qualquer possibilidade de controle. É certo que tais construções arbitrárias não serão exteriorizadas de maneira explícita, mas sim maquiadas por uma suposta legalidade ${ }^{407}$.

Todavia, as teorias da argumentação parecem ter dificuldade em cumprir sua pretensão de conferir racionalidade ao decidir judicial se enxergamos o produto da decisão sob a ótica da igualdade $^{408}$. Tomando por premissa que critérios racionais podem ser racionais em diferentes sentidos ou para atingir diferentes finalidades, um mesmo caso jurídico colocado ao judiciário poderá receber respostas diferentes, mas ainda assim racionalmente justificadas com base em parâmetros de racionalidade distintos. O problema da ausência de base argumentativa parece ser solucionado pelas propostas teóricas argumentativas, todavia a carência de padrões decisórios, que avalizaria a prolação de decisões harmônicas entre si, não tem a mesma sorte.

\footnotetext{
407 Aqui vale repisar os artifícios instrumentalizados pelas decisões no intuito de atalhar suas fundamentações são: a) o uso da doutrina como argumento de autoridade sem a contextualização de sua citação com o caso analisado; b) citação de pedaços de legislação desconectados, em concreto, com a tópica; c) recorrer à jurisprudência também como argumento de autoridade, sem explicitação de sua correlação com o caso. (RODRIGUEZ et al, 2010, p. 40) ${ }^{408}$ A coerência assegura igualdade, isto é, que os diversos casos terão igual consideração por parte dos juízes. Isto somente pode ser alcançado através de um holismo interpretativo, construindo a partir do círculo hermenêutico. Já a integridade significa rechaçar a tentação da arbitrariedade, que, no mais das vezes, é variante da discricionariedade. (STRECK, 2009, p. 319 ss.)
} 
Percebe-se que um caminho para que o problema da carência de padronização seja superado é perseguido pelas propostas com enfoque nas dimensões hermenêuticas de estudo da interpretação jurídica. A construção hermenêutica será aqui exposta mediante os cânones da hermenêutica filosófica de base gadameriana, mediada pela tradução que Lênio Streck dela realiza no âmbito do direito.

Distinção primeva entre o paradigma da hermenêutica filosófica e o das teorias da argumentação está no fato daquela pretender superar o modelo sujeito-objeto de análise, passando para uma lógica intersubjetiva (STRECK, 2013, p. 346). A relação sujeito-sujeito é identificada na própria relação texto-intérprete, não sendo por outro motivo que Gadamer fala em "deixar o texto falar", operando o chamado giro linguístico ao ver o texto também como sujeito (SALGADO, 2008). Sobre o tema, Streck (2009, p. 188-189), assinala:

\footnotetext{
A diferença da postura hermenêutica para as Teorias da Argumentação é que, para a compreensão hermenêutico-filosófica, a resposta correta não decorreria desse juízo de ponderação do juiz, mas, sim, da reconstrução principiológica do caso, da coerência e da integridade do Direito. Seria uma decisão sustentada em argumentos de princípio e não em raciocínios finalísticos (ou de políticas). É por isso que o hermeneuta salta do esquema sujeito-objeto para a intersubjetividade (sujeito-sujeito). Os princípios, justamente por superarem as regras, evitam a subsunção e a discricionariedade e chamam à reconstrução integrativa: o sentido é construído intersubjetivamente, na tradição [...].
}

A partir dessa concepção intersubjetiva, o próprio conceito de interpretação será reconfigurado. Com apoio nas lições de seu mestre Martin Heidegger, Gadamer traçará um perfil da hermenêutica em que não se necessita de uma metodologia para interpretar. A "metodologia é substituída por uma análise filosófica, uma vez que a compreensão deve ser entendida como categoria essencial, ou melhor, fundante da existência humana, sendo essa perspectiva ontológica necessária a qualquer ato do ser" (SALGADO; MIRANDA, 2014, p. 810). Uma crítica, portanto, ao uso do método científico como caminho de acesso à verdade, asseverando que o elemento indicativo desta é, na realidade, a compreensão dos fenômenos linguísticos.

Esta dimensão filosófica do interpretar conduzirá à afirmação de que os sentidos que o intérprete mobiliza para compreender o mundo estão carregados de uma tradição presente em um horizonte histórico. Isto é, o processo interpretativo para a compreensão do hoje derivará necessariamente das cargas de sentido existentes nas compreensões do ontem, ocorrendo a chamada fusão de horizontes. A nossa compreensão é invariavelmente determinada e possibilitada pela tradição, é dizer, nossos juízos sobre algo são pré-juízos ou pré-compreensões fornecidos pela História e reinterpretadas por nós, o que remete a uma estrutura circular da 
compreensão (SALGADO; OLIVEIRA, 2014). A circularidade é mesmo um necessário atributo da linguagem porque, não obstante esteja-se preso à tradição, com suas précompreensões, estas podem não representar a compreensão plena, correta. É nesse contexto que Gadamer (2005, p. 401-402) escorre sobre interpretações corretas e incorretas:

\begin{abstract}
Toda interpretação correta tem que proteger-se contra a arbitrariedade da ocorrência de "felizes ideias" e contra a limitação dos hábitos imperceptíveis do pensar, e orientar sua vista 'às coisas mesmas' (que para os filólogos são textos com sentido, que também tratam, por sua vez, de coisas). [...] A tarefa hermenêutica se converte por si mesma num questionamento pautado na coisa, e já se encontra sempre determinada por este. Com isso o empreendimento hermenêutico ganha um solo firme sob seus pés. Aquele que quer compreender não pode se entregar, já desde o início, à causalidade de suas próprias opiniões prévias e ignorar o mais obstinada e consequentemente possível a opinião do texto - até que este, finalmente, já não possa ser ouvido e perca sua suposta compreensão. Quem quer compreender um texto, em princípio, deve estar disposto a deixar que ele diga alguma coisa por si.
\end{abstract}

É certo que a hermenêutica filosófica não sistematiza uma teoria para a interpretação jurídica. Seu objeto de estudo é a compreensão em geral, o que possibilita sua aplicação a vários campos, inclusive o jurídico. Será, então, essa possibilidade de se encontrar uma interpretação correta, autenticamente afinada com a tradição, a fagulha teórica que permitirá a elaborações no campo da hermenêutica jurídica arquitetar teses que intentem aniquilar a discricionariedade interpretativa dos juízes. Isto é, a invectiva é lançada contra a falta de padronização das decisões decorrentes de juízos arbitrários sobre o sentido das normas, justamente o problema apontado na introdução que supostamente não teria sido solucionado pelas teorias da argumentação.

Não se tenta imprimir racionalidade para a realização da justificação do sentido escolhido, como fazem as teorias argumentativas; o que o horizonte da hermenêutica filosófica pretende, na leitura feita por teóricos da hermenêutica jurídica, é provar que aquela determinada decisão é a correta de acordo com a melhor leitura de uma determinada tradição jurídica.

Utilizando-se a distinção de Atienza (2007, p. 4) entre contexto de descobrimento, no qual se enuncia uma conclusão, e contexto justificação, no qual se avalia razões de tal conclusão ser válida, podemos classificar o horizonte hermenêutico filosófico como uma estrutura normativa de descobrimento do sentido das leis. Com a predicação estrutura normativa de descobrimento pretende-se apontar o interesse da hermenêutica em descobrir a resposta correta, não nos dando opção de escolha entre interpretações possíveis. Não é por outro motivo que Alexy (1995) afirma que a hermenêutica, ao contrário da teoria da argumentação, "nada diz sobre os critérios de confirmação ou rechaço das hipóteses de interpretação", vez que está preocupada com a forma como a descoberta do sentido se opera. 
O olhar aqui lançado para às hermenêuticas jurídicas que surgem a partir da hermenêutica filosófica será, contudo, de desconfiança. As próprias abordagens argumentativas, ademais, lançam contra-argumentos fortes contra os horizontes de bases hermenêuticas, vincando ser desimportante a reconstrução ou a análise da forma como o sentido que atribuímos às coisas é realizado, sendo mais essencial a demonstração, através de argumentos racionais, se tais sentidos são sustentáveis ou não (COELHO, 2011). Frisam que as hermenêuticas seriam capazes de sustentar uma "causa" para nossos sentidos, mas nunca uma razão para eles, sendo este último aspecto muito mais importante na aplicação jurídica:

\begin{abstract}
O processo de formação de uma crença não tem nada a dizer a respeito de sua validade. O relato de sua formação e transformação não pode contar como argumento em favor nem de sua aceitação nem de sua rejeição. Isso porque uma crença formada pelo processo mais irracional pode, quando sustentada por argumentos adequados, mostrar-se válida, ao passo que outra, formada pelo processo mais racional, pode, se sustentada por razões que não conseguem resistir à crítica em contrário, mostrar-se inválida. A racionalidade de uma crença não habita no seu processo de formação, e sim no seu potencial de justificação com base em razões em seu favor e em face de razões em contrário (COELHO, 2011).
\end{abstract}

As suspeitas ao anti-método hermenêutico como adequado para minar a discricionariedade podem ser, em certa leitura, alimentadas pelo próprio Hans-Georg Gadamer quando percebemos que o filósofo alemão em verdade não declarou uma guerra contra o método racional, compreendendo-o como imprestável para a atividadeinterpretativa, mas sim realizou uma crítica no sentido de não ser o ele o mediador de todo acesso à verdade, devendo ser complementado ${ }^{409410}$ (MIRANDA; SALGADO, 2014):

Assim, questiona-se se o campo do direito não pode ser um cenário de aplicação limitada do antimétodo hermenêutico, já que, assim como o método racional, este também seria passível de insuficiências.

Pergunta-se: como o conceito de tradição se adequaria ao direito numa sociedade complexa, principalmente ante a assunção de uma postura não positivista, vinculativa do direito à moral? Como um ordenamento jurídico poderia vincular as interpretações de seus aplicadores aos sentidos colocados na tradição, fazendo os separar as interpretações corretas das

\footnotetext{
409 Se quisermos caracterizar o lugar de meu trabalho dentro da filosofia de nosso século, devemos partir diretamente do fato de que tentei oferecer uma contribuição mediadora entre a filosofia e as ciências, e sobretudo desenvolver de maneira produtiva as questões radicais de Martin Heidegger - às quais agradeço terem proporcionado pontos decisivos no tanto que pude compreendê-las - dentro do amplo campo da experiência científica. Foi isso que me levou necessariamente a ultrapassar o limitado horizonte de interesses da metodologia da teoria da ciência. (GADAMER. 2005, p.509)

${ }^{410}$ Em sentido dissonante, entendendo que a obra da Gadamer representa uma cruzada que tenta superar por completo o método (científico) como forma de acesso à verdade, temos Streck (2009, prefácio).
} 
incorretas $^{411}$ ? O processo de formação dos sentidos tem tanta relevância assim em um ambiente de dever-ser? Só respondendo a estas indagações é que poderemos concluir se avaliar a discricionariedade jurídica sob o horizonte hermenêutico implica ou não no próprio fim do momento discricionário.

Para responder as perquirições levantadas optou-se por estudar a fundo a teoria da resposta adequada à Constituição de Lênio Streck, compreendendo que tal formulação esforçase em oferecer considerações consistentes sobre todas as desconfianças lançadas nos parágrafos anteriores, defendendo ser possível superar a discricionariedade através de um aporte hermenêutico. Por se propor a fazer algo que poucas teorias se propõem, seja por aceitar o momento discricionário como normal, seja por modificar o próprio ideal de segurança jurídica, o conhecimento e avaliação da referida teoria do jurista brasileiro merecem a atenção.

\section{3 É POSSÍVEL MITIGAR A DISCRICIONARIEDADE JUDICIAL PELA TESE DA RESPOSTA ADEQUADA À CONSTITUIÇÃO DE LÊNIO STRECK?}

Deve-se explicar a Tese da resposta adequada à Constituição (TRAC) desenvolvida pelo movimento Crítica Hermenêutica do Direito (CHD) a partir de quatro eixos: a) a explicitação da insuficiência das formulações argumentativas; b) a relação entre direito e moral; c) a diferenciação entre regra e princípio e a ressignificação do papel destas espécies normativas; d) a imbricação entre a influência dworkiana e a hermenêutica filosófica e a importância dos precedentes na compreensão dos sentidos das normas.

3.1 A necessidade de superação das teorias argumentativas/discursivas: o discurso pós método

A impossibilidade das teorias argumentativas/discursivas solverem o problema da concretização do direito residiria no fato de que tais elaborações incorreriam na própria problemática que pretenderiam criticar no positivismo. Explica-se: para as teorias argumentativas a solução para o problema da discricionariedade não é encontrada palmilhando uma investigação sobre o sentido das normas jurídicas. Há um conceito de correção dentro do direito, mas este não implica em poder dizer que uma resposta jurisdicional é correta e outras

\footnotetext{
${ }^{411}$ Sim, pois não haveria utilidade jurídica em diferenciar interpretações autênticas de inautênticas das normas se não pudéssemos dizer que tal interpretação inautêntica simplesmente não é direito e, por tal razão, uma decisão que a mobiliza é passível de reforma ou anulação.
} 
incorretas em termos conceituais. A correção aqui quer significar uma justificação suficiente que pode levar a resposta escolhida a legitimar-se perante a ordem jurídica. A base para a legitimação escora-se muito mais em uma razão discursiva, do que em uma razão linguísticoontológica, hermenêutica. Este movimento, que assume a possibilidade de que várias interpretações possíveis possam ser apresentadas e, após, escolhidas, olvida o irrenunciável caráter hermenêutico inerente ao direito.

Se o modelo positivista, a partir do esquema sujeito objeto, caminhava para enxergar o conjunto de normas como um dado já pronto, de onde seria impossível retirar interpretações dissonantes, a análise argumentativa tem em sua foz a possibilidade de enxergar este mesmo conjunto com variações ilimitadas de sentido construídas a partir da racionalidade prática discursiva. Recai-se, pois, novamente no paradigma analítico do binômio sujeito objeto, mesmo após a hermenêutica filosófica ter demonstrado a falha de tal esquema ao não inserir o intérprete num contexto de interpretação linguístico que necessariamente condicionará sua compreensão ${ }^{412}$.

Um exemplo desse esquecimento seria a divisão feita por Klaus Gunther entre discursos de fundamentação e discursos de aplicação. Os primeiros afeririam a aceitabilidade racional das normas, analisando-as de forma abstrata, e seria realizado principalmente no âmbito legislativo. Já ao segundo importaria a aferição da adequação da norma aos casos concretos, levando-se em conta as circunstâncias tópicas específicas (COELHO, 2011).

Admitindo que em um primeiro momento, ao analisar o discurso de fundamentação, poder-se-ia encontrar objetivamente as possibilidades de interpretação de uma norma para, em um segundo nível, adaptar estas possibilidades ao caso concreto dentro de um discurso de aplicação, tal distinção seria uma expressão da entificação metafísica dos conceitos interpretativos, não assumindo o caráter prático e histórico do direito ${ }^{413}$. Neste sentido é que

\footnotetext{
412 "O processo de reflexividade iniciado com a pergunta transcendental moderna desembocou, hoje, na pergunta pela linguagem como instância intranscendível da expressividade do mundo. A reviravolta lingüística do pensamento filosófico do século XX se centraliza, então, na tese fundamental de que é impossível filosofar sobre algo sem filosofar sobre a linguagem, uma vez que esta é momento necessário constitutivo de todo e qualquer saber humano, de tal modo que a formulação de conhecimentos intersubjetivamente válidos exige reflexão sobre sua infra-estrutura lingüística. É nesse sentido que K.O. Apel vai dizer que a Filosofia Primeira não é mais a pesquisa a respeito da natureza ou das essências das coisas ou dos entes (ontologia), nem tampouco a reflexão sobre as representações ou conceitos da consciência ou da razão (teoria do conhecimento), mas reflexão sobre a significação ou o sentido das expressões lingüísticas (análise da linguagem). A superação da metafísica clássica implica, hoje, a tematização não só da mediação consciencial, como se fez na filosofia transcendental da modernidade enquanto filosofia da consciência, mas também da mediação linguística." (OLIVEIRAa, 2006. p. 1213).

413 "Fundamentalmente, teoria é visão: distinta é a perspectiva. Portanto, conhecimento para a metafísica é essencialmente um trazer para diante dos olhos, do corpo ou do espírito. O que é trazido para diante dos olhos está aí e só pode ser visto enquanto está aí. Por isso o sentido último do ser para esse pensamento é um estar-aípermanente. Se ser é, essencialmente, estar-aí-permanente, ser e história se contrapõem de uma maneira radical, e
} 
Streck sentenciará a impossibilidade de fazermos coincidir discursos de validade com discursos de fundamentação. A validade repousaria em outro substrato, a saber, o respeito aos sentidos cristalizados na tradição da prática jurídica:

\begin{abstract}
Sendo mais claro: é contraditória qualquer perspectiva jus-interpretativa calcada na possibilidade de múltiplas respostas, porque leva, ineroxavelmente, ao cometimento de discricionariedades, fonte autoritária dos decisionismos judiciais. Trata-se, pois, de entender que, se o primeiro problema metodológico - como se interpreta - tem uma resposta que está fundamentada na superação do paradigma representacional, em que não mais cindimos interpretação de aplicação, o segundo - como se aplica - parece bem mais difícil de resolver, isto é, aqui se trata de dar uma resposta talvez ao maior desafio do direito nestes tempos de pós-positivismo: como evitar decisionismos, ativismos, etc, e alcançar uma resposta correta (adequada constitucionalmente) em cada caso. Ou seja, como transformar a Constituição - e a sua interpretação - em um direito fundamental do cidadão, no sentido de que o resultado dessa interpretação não seja fruto de um sujeito solipsista ou dependente de métodos igualmente elaborados a partir do (velho) paradigma representacional. Este é o cerne da discussão hermenêutica, pois (STRECK, 2010, p. 390).
\end{abstract}

Uma desindexação da norma à tradição, com a assunção de que haveria uma validação dos sentidos das normas somente a partir de discursos de justificação seria recair em falhas do positivismo, não assumindo inseparabilidade da interpretação e da aplicação do direito. Nessa ambiência a hermenêutica filosófica distingue-se não só dos horizontes argumentativos, mas também dos horizontes hermenêuticos que se perguntavam pelo sentido das coisas sem levar em consideração a problematização da linguagem. Ou seja, há posturas hermenêuticas ávidas em alcançar uma limitação da possibilidade de atribuição de significados, mas ainda presas ao paradigma do sujeito-objeto e assim entendedoras da linguagem apenas como uma mediadora entre o intérprete e o que se interpreta ${ }^{414}$. Tais orientações, pelos argumentos já tracejados, são também superadas pela hermenêutica filosófica de orientação intersubjetiva ${ }^{415}$.

a metafísica enquanto ciência do ser deve ser fundamentalmente uma ciência a-histórica. Esta decisão dos primórdios marcará todo o pensamento do Ocidente: filosofar vai significar fugir da facticidade da vida e da história, para se situar no plano das idéias eternas, inteiramente distinto da verdadeira vida do homem." (OLIVEIRAa, 2001. p. 117)

${ }^{414}$ Exemplos de posturas hermenêuticas que se voltam contra a concepção de uma possibilidade de múltiplas hermenêutica mas que ainda assim demonstram-se presas ao modelo sujeito-objeto são as formulações de Schleirmacher ( apud, Grondin 1999), formulador da atividade hermenêutica como uma arte do entendimento universal, arte que deveria ter suas regras bem definidas, e Dilthey (1947), que refuta as teses positivistas de que as ciências naturais forneceriam o único modelo científico viável com sua busca pela razão histórica universal a guiar a compreensão.

415 "Gadamer se coloca contra o modelo de hermenêutica tradicional do século XIX, cujo axioma propõe que toda verdade é consequência lógica da aplicação de um método científico (clássico). Assim, faz renúncia expressa à interpretação através de um método único para se alcançar a verdade, porém admite unicamente que há uma prédireção para ela, mediante a compreensão dos fundamentos linguísticos. A hermenêutica é um campo da filosofia que, além de apresentar um foco epistemológico, também estuda o fenômeno da compreensão por si mesmo [...] A partir destas proposições foi necessária a implementação de mudanças que alterariam todo o substrato hermenêutico conhecido até o momento. Isto é, a visão tradicional deve ser superada. Tal mutação fez com que, o que antes era visto como um problema normativo e metodológico (conjunto de métodos e técnicas destinados a 
A demonstração, a partir de uma perspectiva de reconstrução histórica da tradição, de que determinado sentido é o interpretativamente correto consistiria na mais forte argumentação a ser realizada. Compreender corretamente já seria, em grade medida, $\operatorname{argumentar}^{416}$. Só este olhar hermenêutico fortemente anti-relativista, vinca a CHD, é capaz de pôr fim ao caráter relativista que uma abordagem de cariz argumentativo leva à compreensão.

\subsection{A co-originariadade e a complementariedade entre direito e moral}

Passando ao segundo eixo, a CHD reivindicará a autonomia do fenômeno jurídico frente à moral. O conceito de autonomia colocado não é, no entanto, o de separação, mas de distinção, pondo em realce a comunicabilidade entre as duas esferas (LUIZ, 2013, p. 160). A fonte de tal proposta é a relação entre direito e moral na obra de Habermas, que caracteriza a interface dos dois fenômenos como uma relação de "complementaridade recíproca", não surgindo eles de maneira apartada na sociedade, como se o direito derivasse da moral e vice-versa, mas sim emergindo co-originariamente (HABERMAS, 1997, p. 140).

Nesta etapa em que a elaboração streckiana coordena ensinamentos gadamerianos com aqueles habermasianos, necessário pontuar que a conjunção realizada pela teoria do professor gaúcho não padecerá com os atritos teóricos existentes em determinados pontos das formulações dos dois filósofos inspiradores. Habermas criticou na obra de Gadamer a possibilidade de que a compreensão fosse compreendida de maneira cega como uma absorção dos significados impostos pela autoridade da tradição, o que tenderia a dispensar qualquer reflexividade crítica sobre estes sentidos herdados (LIMA, 2008, p. 57). Mesmo considerando que a obra de Gadamer supera tal crítica ao enxergar a compreensão não só como uma submissão ao horizonte da tradição, mas como um plexo que toma em conta também o horizonte do próprio intérprete e do texto (fusão de horizontes), entende-se que a conjugação feita se dá em outro ponto teórico que não aquele em que os citados autores entraram em atrito. O que se toma emprestado de Habermas é especificamente a sua formulação da relação entre moral e direito e não seu ceticismo diante do conceito de autoridade e tradição de Gadamer.

interpretar a essência de um texto ou norma), hoje, passa a ser encarado com um problema ontológico, ou seja, universal e filosófico, que afeta o homem em sua amplitude. (SALGADO; MIRANDA, 2014, p. 81-90).

416 “Com Heidegger, a hermenêutica mudará de objeto, de vocação e de estatuto. Primeiramente, mudará de objeto, deixando de incidir sobre os textos ou sobre as ciências interpretativas para incidir sobre a própria existência. Podemos falar, então, de uma virada existencial da hermenêutica. Ela também mudará de vocação, porque a hermenêutica deixará de ser entendida de maneira técnica, normativa ou metodológica" (GRONDIN, Jean. 2012, p. 38). 
Diga-se também que, muito embora inconciliáveis em certos termos, as teorias de Gadamer e Habermas encontram-se ao conceber a compreensão hermenêutica é necessariamente uma articulação entre a auto compreensão e ação. Ambos reconhecem a necessidade de criticar o método científico moderno como detentor da produção do conhecimento, sendo necessário que o conhecimento seja entendido com uma outra gramática. É dentro desta forma comum de conceber a gênese das categorias sociais, afastada do método científico clássico, que Habermas construirá a sua relação de direito e moral. Portanto, o aspecto utilizado por Lênio da teoria habermasiana encontra-se topograficamente muito mais próximo do ponto de encontro do que do locus de separação entre as duas teorias.

No plano das distinções, a conduta humana será tratada de maneira diferente pelas duas óticas. A moral cuidará tanto do plano interno, acessando os debates da consciência, quanto do plano externo, no atinente à ação dos indivíduos. O direito, por seu turno, influenciará somente as ações e omissões interferentes na realidade material. No aspecto externo, Habermas (1997, p. 149) assinala que a relação da moral com a ação será virtual, dependendo sua interferência da motivação dos próprios atores, que podem agir conscientemente segundo uma moral ou não. A segunda dessemelhança estaria no caráter de obrigatoriedade que o direito encerra, sendo por ele que se garante o poder conformativo do discurso jurídico.

Relegada somente a uma forma de saber cultural capaz de avaliar e orientar o agir, a moral é fenômeno fragilizado, pois não garante no processo de socialização a transferência das orientações do nível do saber para o do agir. A institucionalização de padrões morais realizada pelo discurso jurídico será capaz de fortalecer tais moralidades (LUIZ, 2013, p. 163-165). Ou seja, relação de complementaridade entre direito e moral se daria por ser aquele um dos responsáveis por dotar de institucionalidade discursos morais específicos.

Afastam-se, pois, três teses sobre a relação direito moral no que diz respeito à tomada de decisões jurídicas. A primeira é a do positivismo excludente, na qual se defende que a moralidade não influenciaria de qualquer forma as razões jurídicas mobilizadas na decisão, utilizando-se somente critérios puramente jurídicos ou morais sem juridicidade para o ato de decidir. A segunda tese desconstruída é a do positivismo inclusivo, pela qual critérios morais vindos de fora do ordenamento jurídico, isto é, uma moral não jurídica, poderia fornecer parâmetros para as tomadas de decisão caso o ordenamento assim permitisse por meio de um abertura.do sistema.

Por fim, a proposta também se diferencia das concepções que tomam a moral como eventual critério corretivo do direito na forma como coloca ALEXY (2009, p. 48-76), inspirado na fórmula de Radbruch, quando o diz que "as normas individuais perdem seu caráter jurídico 
e, com isso, sua validade jurídica quando são extremamente injustas”. Este pensar, arquitetado num ambiente de pós-guerra e disposto a proteger o direito de instrumentalizações deletérias à sociedade, render-se-ia a uma lógica axiológica, em que o fundamento último do direito residiria em valores morais comungados socialmente. A crítica feita pela CHD é que esta acepção desaguaria necessariamente em juízos discricionários sobre os valores a serem mobilizados na correção do direito, uma vez que, para orientação axiológica, seria incorreto demandar que estes valores estivessem expostos em alguma positividade ou institucionalidade (NEVES, 1993).

A construção que exsurge após o afastamento dos três pontos de vista anteriores é a de um direito conformado já em afinidade com discursos morais. Não haveria chance de existir uma lei predicada como válida, mas materialmente injusta, como se os campos da moral e do direito estivessem incomunicáveis. A moral está introjetada no direito, não estando dele apartada para ser utilizada quando o intérprete julgar necessário ${ }^{417}$. A própria validade do sentido atribuído à norma, testado em sua aplicação, já depende de uma filtragem hermenêutica que necessariamente mobilizará critérios morais já cristalizados na comunidade. A forma como estes princípios simultaneamente morais e jurídicos são apresentados ao direito será abordada nos parágrafos seguintes.

3.3 A reconfiguração da norma: dimensão regra e dimensão princípio

A TRCA demandará uma reconfiguração também da teoria da norma jurídica. Assim como moral e direito não são conceitos separados, mas sim diferentes, regras e princípios não serão espécies normativas apartadas, como ocorre em muitas abordagens não positivistas, mas sim dimensões distintas de uma norma. Afirma-se que por trás de cada regra haverá um princípio jurídico que a fundamenta e a conforma ao mundo prático. A abertura proporcionada pela dimensão principiológica é informadora de todas as regras do ordenamento (STRECK, 2010, p. 398). No processo aplicativo não se deixa de aplicar uma regra para aplicar um

\footnotetext{
417 “Do mesmo modo, não há como tentar compatibilizar neoconstitucionalismo e positivismo jurídico porque - e isso é ressaltado por Oto - mesmo o primeiro constitucionalismo era contrário ao positivismo, como nos lembra Nicola Matteucci. A questão direito-moral é outra coisa. Daí que - e não tenho receio de afirmar - essa postura massificada que vê no neoconstitucionalismo uma mutação do positivismo jurídico (sic) para nele introduzir a moral através de discursos corretivos/adjudicadores, mostra-se sobremodo equivocada, porque não entende essa "motivação histórica" da qual ele é tributário. Claro, na medida em que todas estas posturas são caudatárias das teorias analíticas lato sensu, elas não "dão conta" do "destino" que a história nos impõe. E isso a hermenêutica pode nos mostrar muito bem, revolvendo o chão lingüístico da história, a partir de uma reconstrução institucional do Estado, do direito e da política". (STRECK, 2010, p. 385)
} 
princípio ou vice-versa, necessariamente os dois estarão sendo mobilizados numa aplicação, interagindo dentro do círculo hermenêutico (STRECK, 2010, p. 402).

Os princípios, antes de tudo, não serão valores; supera-se a visão axiológica de sua natureza para dotá-los de um de cariz deontológico, delimitador da história institucional do direito e originado de um modelo de sociedade resultante de um processo histórico da comumunidade. A visão de princípios como aportes axiológicos os habilita enquanto categoria discursiva, capazes de ser mobilizados pelo intérprete para fazer valer uma discussão, mas não concedem ao princípio uma imperatividade, vez que não são vistos como deveres, mas como orientações a serem perseguidas na medida de um horizonte possível e deveras indeterminado. É tal acepção ainda, contudo, a mais encontrada na jurisprudência, inclusive em precedentes constitucionais, como se vê:

EMENTA: ADMINISTRATIVO. ENSINO SUPERIOR. ESTABELECIMENTO OFICIAL. COBRANÇA DE TAXA DE MATRÍCULA. INADMISSIBILIDADE. EXAÇÃO JULGADA INCONSTITUCIONAL. I - A cobrança de matrícula como requisito para que o estudante possa cursar universidade federal viola o art. 206, IV, da Constituição. II - Embora configure ato burocrático, a matrícula constitui formalidade essencial para que o aluno tenha acesso à educação superior. III - As disposições normativas que integram a Seção I, do Capítulo III, do Título VIII, da Carta Magna devem ser interpretadas à dos princípios explicitados no art. 205, que configuram o núcleo axiológico que norteia o sistema de ensino brasileiro.(RE 510378, Relator(a): Min. RICARDO LEWANDOWSKI, Tribunal Pleno, julgado em 13/08/2008, REPERCUSSÃO GERAL - MÉRITO DJe-202 DIVULG 23-10-2008 PUBLIC 24-10-2008 EMENT VOL-02338-06 PP-01092, grifo nosso)

EMENTA: AÇÕES DIRETAS DE INCONSTITUCIONALIDADE. MEDIDA PROVISÓRIA No 213/2004, CONVERTIDA NA LEI N N $^{\circ} 11.096 / 2005$. PROGRAMA UNIVERSIDADE PARA TODOS - PROUNI. AÇÕES AFIRMATIVAS DO ESTADO. CUMPRIMENTO DO PRINĆÍPIO CONSTITUCIONAL DA ISONOMIA. 1. [...]. 5. Não há outro modo de concretizar o valor constitucional da igualdade senão pelo decidido combate aos fatores reais de desigualdade. O desvalor da desigualdade a proceder e justificar a imposição do valor da igualdade. A imperiosa luta contra as relações desigualitárias muito raro se dá pela via do descenso ou do rebaixamento puro e simples dos sujeitos favorecidos. Geralmente se verifica é pela ascensão das pessoas até então sob a hegemonia de outras. Que para tal viagem de verticalidade são compensadas com esse ou aquele fator de supremacia formal. Não é toda superioridade juridicamente conferida que implica negação ao princípio da igualdade. 6. O típico da lei é fazer distinções. Diferenciações. Desigualações. E fazer desigualações para contrabater renitentes desigualações. A lei existe para, diante dessa ou daquela desigualação que se revele densamente perturbadora da harmonia ou do equilíbrio social, impor uma outra desigualação compensatória. A lei como instrumento de reequilíbrio social. 7. Toda a axiologia constitucional é tutelar de segmentos sociais brasileiros historicamente desfavorecidos, culturalmente sacrificados e até perseguidos, como, verbi gratia, o segmento dos negros e dos índios. Não por coincidência os que mais se alocam nos patamares patrimonialmente inferiores da pirâmide social. A desigualação em favor dos estudantes que cursaram o ensino médio em escolas públicas e os egressos de escolas privadas que hajam sido contemplados com bolsa integral não ofende a Constituição pátria, porquanto se trata de um descrímen que acompanha a toada da compensação de uma anterior e factual inferioridade ("ciclos 
cumulativos de desvantagens competitivas"). Com o que se homenageia a insuperável máxima aristotélica de que a verdadeira igualdade consiste em tratar igualmente os iguais e desigualmente os desiguais, máxima que Ruy Barbosa interpretou como o ideal de tratar igualmente os iguais, porém na medida em que se igualem; e tratar desigualmente os desiguais, também na medida em que se desigualem. 8. [...]. (ADI 3330, Relator(a): Min. AYRES BRITTO, Tribunal Pleno, julgado em 03/05/2012, ACÓRDÃO ELETRÔNICO DJe-055 DIVULG 21-03-2013 PUBLIC 22-03-2013 RTJ VOL-00224-01 PP-00207, grifo nosso)

Rafael Tomaz de Oliveira ao exemplificar, nos clareia como uma concepção deontológica do princípio deveria operar:

Falamos em igualdade como princípio porque em qualquer caso concreto estará em jogo o problema da igualdade que sempre funcionará como um todo referencial para a construção das regras que irão resolver aquele caso na decisão do juiz. Esta, por sua vez, não poderá ser tomada de maneira aleatória, mas sim de acordo com a história institucional (leis, precedentes, Constituição) e pelos princípios morais que ordenam, de forma coerente, a comunidade. (OLIVEIRAb, 2007, p. 188).

As regras, por outro lado, são preceitos democraticamente elaborados que representariam "meios para garantir um estado de coisas desejado" (STRECK, 2010, p.400), sendo indispensáveis para institucionalizar a carga principiológica a legitimá-la. Ao tempo em que a regra institui um princípio quando institucionaliza via uma positivação democrática, o princípio legitima a regra com seu substrato deontológico.

Compreende-se a norma não mais como gênero do qual regra e princípio são espécies, manter tal visão seria repristinar o paradigma metodológico positivista, objetificando metafisicamente as espécies normativas. A nova postura impõe um olhar ontológico no qual a norma interpretada é o produto resultante da compreensão de uma regra a partir da materialidade principiológica (STRECK, 2009, p 264). Para além de espécies normativas, regras e princípios serão dimensões complementares de uma mesma norma.

Conjugando o novo conceito de princípio com a visão de tradição da hermenêutica filosófica, esta dimensão normativa será enxergada tanto como a abertura do sistema jurídico positivo para a facticidade da vida quanto como limitação à possibilidade de se dizer qualquer coisa sobre as deontologias presentes nesse mundo. Em oposição ao afirmado por certas doutrinas pós positivistas, não seria o princípio somente um locus de abertura do direito a critérios meta-jurídicos ou axiológicos. A vinculação dos princípios à tradição molda o seu sentido, impedindo que sejam interpretados das mais variadas formas possíveis. Aí repousa seu papel de fechamento do sistema autônomo do direito.

Na dimensão da regra, a crítica hermenêutica do direito reconhece a importância dos sentidos revelados pelo texto. Isto é, a compreensão não se revela somente no campo do contexto da tradição, necessitando acessar também o texto normativo. Há, pois, limites 
semânticos ${ }^{418}$ proporcionados pelo texto que não poderão ser ultrapassados, mas que constantemente o são, inclusive por meios institucionalizados como súmulas vinculantes e verbetes jurisprudenciais (STRECK, 2010, p. 393). Se for verdade que no novo paradigma constitucional vivenciado o texto não contém a norma jurídica, há de ter-se em mente que esta nunca estará descolada daquele (STRECK, 2005, p. 916-920). A superação da matriz positivista de cunho objetivista, na qual o sentido da norma estava já encerrado no próprio texto, não pode conduzir a um predomínio do modelo subjetivista na compreensão textual, em que o sentido do direito seja completamente dependente do intérprete.

Se assim fosse, as fronteiras hermenêuticas do próprio texto seriam desconsideradas, não se seguindo a recomendação gadameriana para que se deixe o texto falar antes de dizer qualquer coisa sobre o texto. Seu conteúdo seria preenchido com o que a consciência do intérprete/aplicador possuir criatividade para conceber. O fenômeno do desrespeito aos limites semânticos é atestado na seara civil, no contexto da chamada constitucionalização ou publicização do direito civil em que as cláusulas gerais ou conceitos jurídicos indeterminados concedem ao juiz solo fértil para o exercício de uma liberdade interpretativa desvinculada de qualquer critério (JALES, 2013, p. 165) ${ }^{419}$.

O texto é, assim, um evento que possui suas bases, suas balizas; o texto jurídico não fugirá dessa regra, possuindo sim suas reservas absolutas (NOBRE JUNIOR, 2007, p. 43). Tais reservas absolutas limitarão o próprio princípio presente por trás da regra. Exemplificamos: por mais vasta que ela seja, não poderemos extrair da leitura da obra de Pontes de Miranda orientações sobre a boa utilização de um notebook, sendo impossível que leitura de Vidas Secas nos possibilite crer que a história toma lugar em um cenário futurista. $\mathrm{O}$ desrespeito às regras representaria um ataque ao próprio princípio democrático quando a encaramos do ponto de vista legislativo. Não por outro motivo consideráveis correntes constitucionalistas advogam a necessidade da recuperação da dimensão da regra na atividade jurisdicional, freando-se a importância dada aos precedentes, compreendidos estes como topos mais propício à propagação

\footnotetext{
${ }^{418}$ Limites semânticos são entendidos como os sentidos decorrentes do uso pragmático da linguagem que compõe o enunciado. É uma espécie de mínimo que decorre do uso linguístico(...) Assim, se uma lei estabelecer a proibição de circulação de bicicletas em parques nos finais de semana, poderemos- ultrapassada a questão da validade constitucional da norma - discutir os limites de horário, a abrangência da acepção de parques (as praças estariam incluídas) etc. Entretanto, há um ponto que parece indiscutível: a proibição. Ou seja, o intérprete não poderá transformar proibição em permissão, como, por exemplo, fez o STF ao interpretar o art. 212 do CPP. (STRECK, 2014, p. 426).

${ }^{419}$ A título exemplificativo, vejamos o que renomados autores civilistas dizem sobre o processo interpretativo: "In fine, a intepretação pode desaguar em diferentes resultados, a depender do sentido e do alcance firmados pelo intérprete. Assim o resultado da atividade interpretativa poderá ser: 1) ampliativo, ii) restritivo, iii) declarativo, depender do elastecimento ou não do alcance do texto" (FARIAS; ROSENVALD, 2010, p. 80).
} 
da dimensão principiológica ${ }^{420}$. Na medida em que são produções legislativas, as reservas absolutas encerrarão um cariz democrático denso, sendo por isso, a princípio, legitimadas.

Com a reconfiguração da teoria das fontes por parte da CHD, há tanto um limite à discricionariedade exposto pela dimensão da norma enquanto regra, vez que os limites semânticos mínimos não poderão ser ultrapassados, como uma barreira na dimensão principiológica, vez que a tradição será limite à leitura da carga deontológica dos princípios. A problematização que tal arquitetura traz seria a de como esta tradição jurídica presente nos princípios poderia ser lida sem recair ela mesma em leituras discricionárias. Onde estaria cristalizada esta tradição de modo que ela estivesse colocada para que os intérpretes a mobilizem? Como diferenciar pré-compreensões falsas de compreensões legítimas? O eixo abaixo pretende responder tais indagações.

3.4 Diálogo de afluentes: a interpretação construtiva Dworkiana e a Hemenêutica filosófica

É com a metáfora do romance encadeado de Dworkin que Streck orienta-se para solver o problema de onde localizar a tradição hermenêutica dentro da tradição jurídica. Como já frisado, a hermenêutica filosófica desenvolve uma (re)formulação do entendimento direcionado a todo o compreender e não necessariamente ao compreender jurídico. Assim, é necessário por em concordância como a tradição e a autoridade, enquanto conceitos gadamerianos, atuam no processo de transmissão dos sentidos jurídicos. Ronald Dworkin e seus referenciais de coerência e integridade no direito virão contribuir para a visualização da gênese de sentido das normas.

Para o professor americano, o romance encadeado é uma história una, íntegra, concatenada, mas carecedora de um diferente autor para cada distinta etapa de seu desenvolvimento. Desse modo, o escritor de cada capítulo deverá atentar para o que havia sido dito anteriormente por seus parceiros de escrita a fim de guardar a coerência da história em construção, não podendo, pois, dizer o que bem entendesse em seu capítulo próprio. Dworkin (2002) exemplifica tal necessidade ao narrar que uma personagem que houvera sido morta em páginas anteriores não poderia nas seguintes aparecer, injustificadamente, a participar de um diálogo trivial.

\footnotetext{
420 “Ainda que o princípio da legalidade, em suas diferentes aplicações e graus, seja central ao Estado de Direito, a realidade atual mostra que há uma subvalorização lei e sobrevalorização da jurisprudência, vilipendiando, assim, os pilares da modernidade jurídica, no qual se superou o primado da vontade pelo primado da legislação" (MARRAFON; ROBL FILHO, 2014, p. 1439).
} 
A produção de sentido sobre os ombros dos aplicadores deveria ser realizada, pois, de forma semelhante àquela com que os autores escrevem a chain novel. Guarda-se o conhecimento adquirido nas produções de sentido anteriores para desvelarem-se os novos sentidos das normas perante os casos concretos colocados em Juízo, garantindo-se a coerência do sistema (JALES, 2013, p 160.). Passa-se a entender a produção histórica do sentido das normas como limite para a atribuição de significado em novas decisões judiciais. A facticidade presente na dimensão principiológica resta cristalizada na própria positividade na medida em que nos precedentes se cravam substratos deontológicos encontrados nos contextos de aplicação passados. São eles, os precedentes, as expressões da comum-unidade da tradição das instituições jurídicas e dotarão de coerência e integridade o sistema.

\begin{abstract}
Sem mais, o onírico Romance em cadeia é um artifício para sublinhar alguns aspectos importantes para a compreensão e interpretação do Direito. Em primeiro lugar, assim como a estória romanceada, o Direito deve ser entendido como um todo coerente. Este pressuposto, colhido da filosofia kantiana, demonstra a aceitação, pelo autor, da ideia de uma racionalidade ancorada e inerente a nossas práticas continuadas. Isto porque, chamados a decidir um caso concreto, os juízes poderão sempre optar racionalmente por uma resposta e se há subjetivismos nas decisões é preciso ressalvar em que sentido isto deve ser compreendido. Em segundo lugar, as decisões de casos concretos no Direito devem levar em conta toda a história institucional que as precede. Como no Romance em cadeia, não se pode aqui alvitrar algo em desarrimo com o que já foi fornecido como elemento para a escolha de uma direção (TRAVINCAS, 2007, p. 5)
\end{abstract}

Esta coerção produzida pelas decisões do passado implica no condicionamento da intepretação construtiva aos fundamentos utilizados nas tomadas de decisões pretéritas. A intepretação construtiva ${ }^{421}$ é, para além do conceito dworkiano de interpretação, seu próprio ideal do interpretar. Esta categoria concebe a interpretação de determinada coisa como aquele sentido que coloca esse objeto "sob sua melhor luz". Em outras palavras, e interpretação construtiva primeiro contextualiza o objeto interpretado em uma determinada prática para em seguida atribuir-lhe o significado que lhe proporcione melhor o valor possível dentro daquela prática. Será justamente essa específica forma de atribuição de valor que não será livre, estando condicionada à tradição (COELHO, 2012b).

Percebe-se, pois, a sutil interseção entre a tese Dworkiana e a hermenêutica filosófica no que diz respeito à necessidade de observância e respeito a uma narrativa histórica prévia. É

\footnotetext{
421 “Em linhas gerais, a interpretação construtiva é uma questão de impor um propósito a um objeto ou prática, a fim de torná-lo o melhor possível da forma ou gênero aos quais se imagina que pertençam. Daí não se segue, mesmo depois dessa breve exposição, que um intérprete possa fazer de uma prática ou de uma obra de arte qualquer coisa que desejaria que fossem; que um membro da comunidade hipotética fascinado pela igualdade, por exemplo, possa de boa-fé afirmar que, na verdade, a cortesia exige que as riquezas sejam compartilhadas. Pois a história ou a forma de uma prática ou objeto exerce uma coerção sobre as interpretações disponíveis destes últimos, ainda que, como veremos, a natureza dessa coerção deva ser examinada com cuidado. Do ponto de vista construtivo, a interpretação criativa é um caso de interação entre propósito e objeto. (DWORKIN, 2000, p .64).
} 
certo que a tradição referida por Dworkin quando vinca a necessidade de respeito aos precedentes para manutenção da integridade não está em completa sinonímia com a tradição Gadameriana. Esta última diz sobre a miríade de valores, crenças e condutas que erigem uma comunidade. Será a partir dela que nós nos constituiremos enquanto agentes no mundo, interpretando o ambiente e agindo sobre ele. Não há qualquer institucionalidade em seu fundamento, sendo continuamente transformada e estando nós necessariamente condenados a compreender a vida a partir dela. Em Dworkin a tradição possui um objeto menor, trata-se da tradição jurídica institucionalizada nas manifestações jurisdicionais do passado que, justamente por essa institucionalização, são dotadas de autoridade e devem ser seguidas pelos aplicadores (COELHO, 2012a)

Mesmo com tais diferenças, as duas concepções de interpretação são claramente antidiscricionárias e antirelativistas, não admitindo que a compreensão seja orientada pela convicção pessoal do intérprete e preocupando-se com as condições pré-interpretativas em que a compreensão das normas ocorre (LUIZ, 2013, p.177). Streck abraça, então, a tarefa hercúlea de pôr fim a discricionariedade do direito, deixando de encarar essa aniquilação como uma possibilidade para tê-la como uma necessidade (STRECK, 2010, p. 405). Em verdade, vê-la como necessidade só é viável quando atestada a possibilidade da resposta correta ser encontrada, o que, pela sua tese, passa a ser completamente viável após a conjugação das leituras anti-relativistas de Gadamar e anti-discricionária de Dworkin:

\footnotetext{
Negar a possibilidade de que possa existir (sempre) - para cada caso - uma resposta conformada à Constituição - portanto, uma resposta correta sob o ponto de vista hermenêutico -, pode significar a admissão de discricionariedades interpretativas, o que se mostra antitético ao caráter não-relativista da hermenêutica filosófica e ao próprio paradigma do novo constitucionalismo principiológico introduzido pelo Estado Democrático de Direito, incompatível com a existência de múltiplas respostas. É possível - e necessário - dizer, sim, que uma interpretação é correta e a outra é incorreta. Movemo-nos no mundo exatamente porque podemos fazer afirmações dessa ordem. E disso nem nos damos conta. (STRECK ,2010, p. 396)
}

A resposta adequada à Constituição, assim como a tese da única resposta correta de Dworkin é também uma metáfora, artifício que pretende explicitar um meio de superar tanto o grau máximo de sentido falaciosamente proposto pelas teorias positivistas quanto o grau zero de significação em que recaem posturas pós positivistas de matiz decisionista. A Resposta Constitucionalmente Adequada nem será a única resposta adequada nem uma entre várias respostas adequadas, mas sim uma busca, sem total garantia de sucesso de alcance, pela resposta hermeneuticamente adequada ao caso. 
Questão essencial na elaboração será a postura do intérprete. Assim como a teoria da única resposta correta Dworkin formula o ideal de Juiz Hércules, reconstrutor da história interpretativa do direito, Streck necessita de um Juiz autoconsciente de seus limites interpretativos para sua tese. O juiz Streckiano deve ser capaz de refletir criticamente sobre seus pré-juízos, suspendendo suas pré-compreensões e separando as de natureza autêntica das de caráter inautêntico. O crivo para tal separação será o próprio círculo hermenêutico possibilitado pela fusão dos horizontes do próprio intérprete, do texto, e do substrato material principiológico presente na tradição jurídica e cristalizado nos precedentes. Veja-se como o distanciamento das pré-compreensões e a consequente avaliação delas é mesmo uma condição de possibilidade para que se atinja a resposta adequada.

A recepção da tese do direito como integridade de Dworkin merecerá adequações por parte de Streck, tendo em vista que as fontes jurídicas nas quais o pensamento jurídico dworkiano baseou-se apresentam, prima facie, conteúdo diverso em nosso modelo de normatividade. Poder-se-ia questionar, por exemplo, que o papel que as decisões judiciais teriam como fonte de sentido em uma atmosfera de civil law, como é o caso do Brasil, seria bastante mitigado em relação aos sistemas de common law. Streck (2009) muito bem contraargumenta sobre lembrando que, embora não possuam porte de legislação, a atenção ao precedente assegura mesmo uma concretização do princípio da igualdade, no sentido de que situações análogas não receberiam tratamento díspares dentro de um mesmo sistema jurídico (JALES, 2013, p.162). ${ }^{422}$

Concomitantemente, enxerga-se que a legitimidade com que esses limites sobrevivem não decorre simplesmente do fato deles terem sido desenhados por precedentes judiciais, mas sim pelo fato destes precedentes refletirem uma compreensão/aplicação fundamentada constitucionalmente, justificada a partir herança da tradição da instituição jurídica. Evita-se que a necessidade de vinculação aos precedentes judiciais pretéritos, ao invés de afastar

\footnotetext{
422 "Se é despiciendo dizer que o sistema jurídico brasileiro não está sustentado em análise de precedentes, como a common law, é necessário lembrar, entretanto, que tal circunstância não retira a importância dos precedentes jurisprudenciais. Ao contrário: uma aplicação integrativa e coerente do direito deve, necessariamente, levar em conta o modo pelo qual um determinado tribunal ou como os outros tribunais do país vêm decidindo determinada matéria. A coerência assegura igualdade, isto é, que os diversos casos terão igual consideração por parte dos juízes. Isto somente pode ser alcançado através de um holismo interpretativo, construindo a partir do círculo hermenêutico. Já a integridade significa rechaçar a tentação da arbitrariedade, que, no mais das vezes, é variante da discricionariedade." (STRECK, 2009, p. 319 ss.)
} 
arbitrariedades e decisionismo, transmute-se em mandamento para que nos ajoelhemos perante enunciados de sentido de aplicação geral (precedentes).

A tradição não substituirá jamais a necessidade de fundamentação/justificação das decisões. Contudo este exercício argumentativo estará limitado pelo prisma não metodológico da hermenêutica. Isto é, a tradição e os constrangimentos epistemológicos da prática impedem que o julgador utilize-se de uma argumentação com conteúdo atemporal (STRECK, 2010, p. 409), sendo o fundamentar um alumiamento e justificação do fenômeno hermenêutico e interpretativo que se encontra velado. Implicação desta mesma premissa é de que a resposta adequada nunca será a resposta definitiva. Com o sentido histórico e de movimentação da tradição, assumindo ser 'o tempo o nome do ser' (STRECK, 2010, p. 410), avaliza-se a constante possiblidade de modificação dos sentidos das normas.

Dito de outro modo, se a atribuição de sentido não se confunde com uma teoria da argumentação também dela não prescindirá (STRECK, 2009, p. 365), sob pena de ceder espaço para a proliferação de uma tradição inautêntica. O encalço de Streck mais uma vez nos orienta:

\begin{abstract}
A possibilidade de se obter respostas corretas não está,pois, na vinculação pura e simples dos precedentes judiciais, mas sim na fundamentação/justificação da síntese hermenêutica que somente ocorre na aplicativo. [...] Tal menção (a um precedente) pode confortar ou demonstrar a viabilidade jurídica de um entendimento, mas nunca fundamentar per si, a decisão (STRECK, 2009, p. 328- 329).
\end{abstract}

A conjugação da identificação do direito como integridade, fundado na coerência e na tradição, com a necessidade de um discurso argumentativo justificador da manutenção ou evolução desta tradição, nos conduz a desvelar, para cada caso diante do qual se aplica/interpreta a norma jurídica, um sentido, uma resposta adequada à Constituição, como denomina Streck.

Outra assimilação se dá na influência da normatividade constitucional sobre o sistema de precedentes. Em primeiro lugar, é sabido que o estudo dworkiano emergirá no contexto norte-americano, possuidor de uma Constituição sintética, onde nem todos os princípios regentes da sociedade estão expressos do texto constitucional. Esta circunstância dará azo à necessidade de buscar os pilares que sustentam a integridade do sistema e a tradição jurídica fora da Constituição, seja na moralidade contida originalmente na legislação infraconstitucional ou mesmo nos precedentes. Em terras tupiniquins o contexto é outro. Possuímos uma Constituição analítica, que intenta preencher de sentido todas as dimensões jurídico-sociais 
através de uma principiologia que coloca com mais ênfase e importância a leitura moral advinda da própria Constituição ${ }^{423}$.

Aqui, então, se opera a principal distinção entre as elaborações de Dworkin e a de Lenio Streck. Nos países de onde Dworkin decola para esboçar sua teoria as Constituições apresentam textos sintéticos, com baixa densidade deontológica. As decisões terão uma amplitude de princípios a mobilizar muito amplo, encontrando-os muitas vezes somente em outras decisões judiciais não na Constituição. A tese de Streck denomina-se de "tese da resposta adequada à Constituição" justo por compreender que o próprio texto Constitucional brasileiro, analítico e rico em normas de alta dimensão principiológica, já fornece um primeiro nível de orientação hermenêutico. A este primeiro nível será conjugado o segundo, representado pelos precedentes judiciais, que fornecerão uma nova camada de constrangimentos interpretativos ao aplicador.

É dizer, se uma Constituição analítica já diminui o grau de abstração dos sentidos das normas, uma valorização dos precedentes tende a esclarecer ainda mais os conceitos normativos, restringindo a discricionariedade.

\section{CONSIDERAÇÕES FINAIS}

Dentre as propostas pós positivistas ou não positivistas, dividimos duas categorias de reações à discricionariedade. A primeira, retomando a razão prática, encara o direito como um projeto argumentativo. Nesse sentido as decisões seriam fundamentadas na medida em que racionalmente pudessem ser justificadas. Demonstrou-se que, muito embora a evolução das teorias desta natureza pudessem nos ajudar a superar uma das crises em que o judiciário encontra-se empacado, a saber, a da carência de justificação nas decisões, elas não foram suficientes para superar a carência de coerência entre as decisões judiciais.

\footnotetext{
${ }^{423}$ Denota-se que a leitura moral que não se permite é aquela que fuja do teor moral que a própria Constituição encerra, sendo, por óbvio, impossível que qualquer texto jurídico não contenha, em si próprio, determinada substância moral. Ainda, esclarece-se que o modelo de discurso jurídico proposto vai reclamar que toda decisão seja fundada a partir da principiologia constitucional, entendida esta como a legítima expressão dos valores essenciais a comum-unidade. Não se podendo admitir, portanto, a utilização de uma norma deontológica contrária ou ausente daquilo que o sistema principiológico constitucional prevê. Nesse sentido: "Dworkin fala em leitura moral por diversos fatores. Entre eles está certamente o fato de que os Estados Unidos da América possuírem uma Constituição que pode ser chamada de sintética, no interior da qual muitos princípios não estão efetivamente constitucionalizados, a ponto de Dworkin falar em uma leitura moral da Constituição. Entre nós, contudo, a situação é outra. Simplesmente porque, com a constituição de 1988 se deu a constitucionalização de toda uma principiologia que, podemos afirmar sem medo de errar, torna desnecessária qualquer tipo de leitura moral. A própria Constituição é, em última análise, moralizante (OLIVEIRA, 2007, p. 205)
} 
Ainda neste pórtico fundamentamos a necessidade de ir além das abordagens argumentativas, principalmente tendo em conta a aplicação do princípio da igualdade também em relação a intepretação da lei. É dizer, a igualdade não deve ser praticada somente diante da lei, mas também diante da aplicação da lei.

Só encontramos teses que busquem superar este segundo problema em abordagens que partem de um ponto de vista hermenêutico do direito. Assim, foram colocadas a prova as propostas de compreensão do direito sobre a ótica hermenêutica como tentativas de atribuir coerência e integridade ao sistema. Para fins de testes, elegeu-se a Teoria da Resposta Adequada à Constituição de Lênio Streck como amostra a ser investigada em nome de variadas teses de fundo hermenêutico.

Este experimento mostrou que a citada abordagem, em virtude das concepções com as quais entende a relação entre direito e moral, a leitura que faz dos institutos das regras e dos princípios, a maneira a-metódica com que compreende o próprio processo de compreensão do ser humano e, por fim, a forma como entende-se que tal teoria cristaliza e apresenta os sentidos das normas jurídicas nos precedentes pode, sim, fornecer as bases epistêmicas e normativas para vincar que o direito possui um horizonte hermenêutico capaz de dotar sua aplicação de coerência e integridade, controlando, assim, de forma mais eficaz a atuação do judiciário.

Não se conclui que a discricionariedade ou o poder criativo dos juízes é totalmente afastado da aplicação jurídica, mas defende-se que este processo é muito mais estreito do que pretendiam as propostas positivistas ou mesmo as propostas pós-positivistas de cunho argumentativo, pois haveria a barreira da tradição jurídica cristalizada nos precedentes a ser superada.

\section{REFERÊNCIAS}

Conceito e validade do direito. Tradução: Gercélia Batista de Oliveira Mendes. São Paulo: Martins Fontes, 2009

.Teoría del discurso y derechos humanos Bogotá: Universidad Externado de Colombia, 1995

ATIENZA, Manuel. Las razones del derecho: Teorías de la argumentacíon jurídica. Universidad Nacional Autónoma de México, 2007. 
Teoria do Direito e Decisão Racional: Temas de Teoria da Argumentação Jurídica.

Rio de Janeiro: Renovar, 2008.

BRASIL. Supremo Tribunal Federal. Ação Direta de Inconstitucionalidade $n^{\circ} 3330$ do Tribunal Pleno do Supremo Tribunal Federal Brasília, DF, 03 de maio de 2012.

Supremo Tribunal Federal, Recurso Extraordinário no 510378, do Tribunal Pleno do Supremo Tribunal Federal, Brasília, DF, 13 de agosto de 2008.

COELHO, André. Abordagem Hermenêutica e Abordagem argumentativa do Direito. Publicado em: 22 dez 2011. Disponível em: $<$ http://aquitemfilosofiasim.blogspot.com.br/2011/12/abordagem-hermeneutica-eabordagem.html>. Acesso em: 12 mar 2015

Exposição e Crítica de Ronald Dworkin: a hipótese estética. Publicado em 17 out 2012a. Disponível em: <http://aquitemfilosofiasim.blogspot.com.br/2012/10/exposicao-ecritica-ronald-dworkin.html>. Acesso em: 15 fev 2015.

\section{Dworkin e Gadamer: Por que Dworkin não é um filósofo hermenêutico?}

Publicado em 17 out 2012b. Disponível em:

>http://aquitemfilosofiasim.blogspot.com.br/2012/10/dworkin-e-gadamer-por-que-dworkin-nao-

e.html>. Acesso em: 14 fev 2015.

DILTHEY, Wilhelm. Le monde de l'estrit. Trad. M. Remy. s./l.: Aubier, 1947.

DWORKIN, Ronald. Levando os direitos a sério. São Paulo: Martins Fontes, 2002.

O Império do Direito. São Paulo: Martins Fontes, 2000

GADAMER, Hans-Georg. Verdade e método. Tradução de Flávio Paulo Meurer (revisão da tradução de Enio Paulo Giachini). 7. ed. São Paulo: EDUSF, 2005.

HABERMAS, Jurgen. Direito e Democracia: entre a facticidade e a validade. Rio de Janeiro: Boitempo, 1997.

GRONDIN, Jean. Introdução à hermenêutica filosófica. Tradução de Benno Dischinger. São Leopoldo: Unisinos, 1999 (Coleção Focus).

JALES, Túlio de Medeiros. Fundamentação das decisões e limites da interpretação/aplicação das normas. Revista Direito e Liberdade, Natal, v. 15, n. 2, p. 146-172 maio/ago. 2013 
LIMA, Aluísio Ferreira de. Hermenêutica da Tradição ou Crítica das Ideologias? O Debate Entre Hans-Georg Gadamer \& Jürgen Habermas UNOPAR Cient., Ciênc. Human. Educ., Londrina, v. 9, n. 1, p. 55-62, Jun. 2008.

LUIZ, Fernando Vieira. Teoria da Decisão Judicial: dos paradigmas de Ricardo Lorenzetti à resposta adequada à Constituição de Lênio Streck. Porto Alegre: Livraria do Advogado, 2013

MARRAFON, Marco Aurélio; ROBL FILHO, Ilton Norberto. A crise das fontes jurídicas enquanto crise do Estado Democrático de Direito. Revista Eletrônica Direito e Política, Programa de Pós-Graduação Stricto Sensu em Ciência Jurídica da UNIVALI, Itajaí, v.9, n.3, $3^{\circ}$ quadrimestre de 2014. Disponível em: <www.univali.br/direitoepolitica>. Acesso em 10 mar 2015 .

NEVESa, Antônio Castanheira. Metodologia jurídica. Coimbra: Coimbra editora, 1993.

NOBRE JÚNIOR, Edilson Pereira. Sentenças aditivas e o mito do legislador negativo. Revista da ESMAFE - Escola da Magistratura Federal da 5ª Região, Recife, PE, n. 12, p. 51-96, mar. 2007

OlIVEIRAa, Manfredo Araújo. A Filosofia na Crise da Modernidade. 3. ed. São Paulo: Loyola, 2001.

Reviravolta linguístico-pragmática na Filosofia Contemporânea. 3. ed. São

Paulo: Loyola, 2006.

OLIVEIRAb, Rafael Tomaz de. O conceito de princípio entre a otimização e a resposta correta: Aproximações sobre o problema da fundamentação e da discricionariedade das decisões judiciais a partir da fenomenologia jurídica. Dissertação (Mestrado). São Leopoldo, UNISINOS, 2007.

RODRIGUEZ, José Rodrigo. Como decidem as cortes? Para uma crítica ao direito (brasileiro). $1^{\text {a }}$ ed. Rio de Janeiro: Fundação Getúlio Vargas. 2013.

et al. Processo leguslativo e controle de constitucionalidade: as fronteiras entre o direito e a política. Brasília: Secretaria de Assuntos Legislativos do Ministério da Justiça do Brasil/CEBRAP, 2010.

SALGADO, Ricardo Henrique Carvalho. A Fundamentação da Ciência Hermenêutica em Kant. Belo Horizonte: Decálogo, 2008. 
SALGADO, Ricardo Henrique Carvalho; MIRANDA, D. C. . A contribuição da Hermenêutica Filosófica para a compreensão do Direito e sua aplicação. In: Artur Stamford da Silva; Rubens Beçak; Margareth Anne Leister. (Org.). XXIII Congresso Nacional do CONPEDI. 1ed.Florianópolis: Conpedi, 2014, v. , p. 71-97.

SALGADO, Ricardo Henrique Carvalho; OLIVEIRA, P. C. P. Gadamer e Dworkin. Confluências entre a Hermenêutica Filosófica e a Interpretação Construtiva do Direito. In: CONPEDI - FUNJAB/UFF. (Org.). Hermenêutica - XXI Congresso Nacional do CONPEDI. 1ed.Florianópolis: FUNJAB, 2012, p. 223-251..

STRECK, Lênio Luiz Hermenêutica, neoconstitucionalismo e o Problema das discricionariedade dos Juízes. Revista Anima. 1ª ed. Vol. 1, p. 383-413. 2010.

Verdade e Consenso: constituição, hermenêutica e teorias discursivas da possibilidade à necessidade de respostas corretas em direito. 3. ed. Rio de Janeiro: Lumen Juris, 2009.

Da interpretação de textos à concretização de direitos: A incindibilidade entre interpretar e aplicar- contributo a partir da hermenêutica filosófica. Revista da Faculdade de Direito da Universidade de Lisboa, Lisboa, v. XLVI, n. 2, p. 911-954, 2005. Disponível em: <http://www.fd.ul.pt/LinkClick.aspx?fileticket=yv9pnpOdkK4\%3D\&tabid=266>. Acesso em: 19 out. 2012.

Porque a discricionariedade é um grave problema para Dworkin e não o é para Alexy. Revista Direito e Práxis Vol. 4, n. 7, 2013, pp. 343-367.

Súmulas, vaguezas e ambiguidades: necessitamos de uma teoria geral dos precedentes? Direitos Fundamentais \& Justiça, v. 5, p. 162-185, 2008. Disponível em: <http://www.dfj.inf.br/Arquivos/PDF_Livre/5_Doutrina_7.pdf >.

Hermenêutica Jurídica $\mathbf{e}(\mathbf{m})$ crise: uma exploração hermenêutica da construção do direito. $11^{\circ}$ ed. Porto Alegre: Livraria do Advogado, 2014.

ALEXY, Robert. Conceito e Validade do direito. São Paulo: Martins Fontes, 2009.

TRAVINCAS, Tradição, coerência (e discurso?): Elementos para uma interpretação correta do direito em Ronald Dworkin. (Artigo apresentado como requisito para a conclusão do Projeto de Pesquisa "A Teoria do Direito de Ronald Dworkin", realizado no período de agosto/2006 a dezembro/2007, na Unidade de Ensino Superior Dom Bosco - UNDB). São Luís, 2007. Disponível em: <http://www.ihj.org.br/pdfs/Artigo_Amanda_Thome.pdf>. Acesso em: 30 dez. 2012. 


\title{
HERMENEUTIC PROPOSALS FOR JUDICIAL APLICATION AND MITIGATION OF JUDICIAL DISCRETION
}

\begin{abstract}
The paper presents the hermeneutical theories for interpreting and applying the law as formulations that aim to constrain judicial discretion at a level that the argumentative theories dare not go. The Thesis Proper Response to the Constitution offered by the Law Hermeneutics Critics movement will be the hermeneutic framework that will serve as a sample to demonstrate that a constraint on the legal tradition is rather capable of operating restrictions on the application of the act of law by the interpreter.
\end{abstract}

Keywords: Legal Hermeneutics. Philosophical Hermeneutics. Hermeneutics of law critical. Theory of Proper Response to the Constitution. 